\title{
Cooler Heads Prevail: An Experimental Study on the "Cooling" Effect of the Strategy Method on Agent Resentment
}

\author{
Jing L. Davis \\ Chapman University, Orange, USA \\ Email: jindavis@chapman.edu
}

How to cite this paper: Davis, J.L. (2018) Cooler Heads Prevail: An Experimental Study on the "Cooling" Effect of the Strategy Method on Agent Resentment. Theoretical Economics Letters, 8, 854-860. https://doi.org/10.4236/tel.2018.85060

Received: February 25, 2018

Accepted: April 5, 2018

Published: April 8, 2018

Copyright $\odot 2018$ by author and Scientific Research Publishing Inc. This work is licensed under the Creative Commons Attribution International License (CC BY 4.0).

http://creativecommons.org/licenses/by/4.0/

\begin{abstract}
This study investigates whether agents' resentment of controls in a gift-exchange game can be effectively mitigated using the strategy method where agents' effort choices are elicited contingent on all possible contract choices by principals. The results suggest that allowing agents to contemplate contract choices prospectively results in less resentment and that agents exert higher effort than without this "cooling" process.
\end{abstract}

\section{Keywords}

Strategy Method, Hidden Cost of Controls, Gift-Exchange Game

\section{Introduction}

Prior experimental studies documented a hidden cost of controls [1] [2] [3]. In a principal-agent setting, this phenomenon occurs when agents' intrinsically motivated effort which otherwise would be present in the absence of controls is withheld in the presence of controls. This is explained by agents' resentment due to the perception of principals' choice of controls as a signal of distrust [4].

Since it is desirable for principals to maintain controls to align agents' interests with their own, it is important to explore ways to mitigate the resentment caused by an imposition of controls. Xiao et al. [5] successfully demonstrated one mechanism to reduce emotional resentment which resulted in significant lower rates of rejections-allowing responders to express their sense of unfairness to proposers in an ultimatum game. Another mechanism, examined by this study, provides agents an opportunity to evaluate the situation more carefully when controls are chosen in an attempt to "cool" their emotional responses. 
Brandts et al. [6] conducted a survey study on behavioral differences between the direct response method (also called as "Hot" method) and the strategy method (also called as "Cold" method). In the "Hot" method, the second mover responds to the first mover's observed action while in the "Cold" method, the second mover decides on a contingent action for every possible move by the first mover without first observing the first mover's action. While the results on behavioral differences between these two elicitation methods are mixed, the traditional prediction is that players may react more emotionally and less strategically when asked "on the spot" in the "Hot" condition than when asked to provide decisions for all alternative choices in the "Cold" condition".

This study conducts a gift-exchange experiment that investigates whether the "Cold" method can be effective in mitigating agents' resentment when controls are chosen by principals. Principals choose between two commonly used contracts in practice: a trust contract (an example of fixed wage contract) in which principals have no controls over agents' effort and a control contract (an example of implicit contract) in which principals can use a punishment if agents fail to provide the desired effort. Two treatments are administrated. The Hot treatment uses the direct response method to elicit agents' effort choices, whereas the Cold treatment uses the strategy method to elicit agents' effort choices.

The results support the traditional prediction, in that when principals choose the control contract agents exert higher effort in the Cold treatment than the Hot treatment. These results suggest that the hypothetical elicitation of decisions "forces" agents to think through both contracts more carefully. This process appears to "cool down" their resentful emotions of controls resulting in higher effort as compared to when they lack this opportunity and their responses are elicited "on the spot".

While prior studies found no behavioral differences in an ultimatum game [7], a trust game [8] and a public goods game [9],this study adds to the literature collected in the survey study of [6] by examining a gift-exchange game. In addition, this study sheds light on the potential usefulness of a "cooling" mechanism for managers in effectuating controls. Finally, the study discusses interpretations of the findings and suggestions for future research on exploring the determinants of behavioral differences between these two methods.

\section{Method}

This study employs two contracts which are both based on a gift-exchange game [10]. In the trust contract, in stage 1 , the principal offers a wage $w$ and requests a desired effort level $\hat{e}$, where $\hat{e} \in\{0.1, \cdots, 1\}$. In stage 2 , in return the agent selects an effort, $e$, where $e \in\{0.1, \cdots, 1\}$. The principal's earnings are $e(120-w)$. The agent's earnings are $w-c(e)$, where $c(e)$ is the cost of effort to the agent. The relationship between effort and costs is shown below:

${ }^{1} \mathrm{~A}$ complete discussion on the behavioral difference between the strategy method and direct response method can be found in [6]. 


\begin{tabular}{ccccccccccc}
\hline $\mathrm{e}$ & 0.1 & 0.2 & 0.3 & 0.4 & 0.5 & 0.6 & 0.7 & 0.8 & 0.9 & 1 \\
\hline $\mathrm{c}(\mathrm{e})$ & 0 & 1 & 2 & 4 & 6 & 8 & 10 & 12 & 15 & 18 \\
\hline
\end{tabular}

In the control contract, the first and second stage are identical to those in the fixed wage contract. After stage 2, a third stage was added, in which the principal had an option to punish the agent at a cost of 2 if the agent's actual effort is lower than the desired effort. It is costless if the principal decides not to punish. When the punishment is chosen, it reduces the agent's payoff by 6 . Assuming individuals only care about their own payoff, the equilibrium strategy under both contracts is for the principals to offer $w=20$ and the agents' best response is to choose $e=0.1$, and $\hat{e}$ is not payoff relevant.

Two treatments were conducted. In the Hot treatment, the principal decides which contract to offer. The agent chooses effort after learning the principal's contract choice. In contrast, in the Cold treatment, the agent chooses effort before learning the principal's contract choice contingent on both contracts being offered.

The Hot treatment consisted of 5 sessions with 130 total participants. The Cold treatment consisted of 2 sessions with 40 total participants. All participants were undergraduate volunteers from The Ohio State University. In all treatments principals and agents are re-matched after each period and interacted for ten periods. The experiments were computerized, using $\mathrm{z}$-Tree [11]. The timeline of decisions is shown in Figure 1. Both the Hot and the Cold treatment begin with the principal choosing to offer either a trust contract or a control contract. Next, the principal offers a wage and requests a desired effort level. In response, the agent chooses an effort level. If a control contract is offered, the principal then decides whether to use a punishment, while if a trust contract is offered, no punishment is allowed. The only difference between the two treatments is that in the Hot treatment the agent makes only one effort choice after observing the principal's contract choice, whereas in the Cold treatment the agent makes two contingent effort choices before observing the principal's contract choice.

The focus of this study is on a comparison of agents' effort in the Hot treatment and agents' effort in the Cold treatment when principals choose the control contract. Higher agents' effort in the Cold treatment than the Hot treatment would suggest that agents' resentment of controls appears to be mitigated when they are given an opportunity to "cool down" and think through principals' contract choices.

\section{Results}

The main results are presented as follows.

RESULT 1. When principals choose the control contract, agents' effort and principals' payoffs are higher in the Cold treatment than in the Hot treatment.

Summary statistics are found in Table 1 . Average effort in the Cold treatment 
when control is chosen is 0.4 , while in the Hot treatment the average effort is 0.35 (Wilcoxon-Mann-Whitney test, $\mathrm{p}=0.01$ ). Additionally the principals' earnings in the Cold treatment when control is chosen are on average 28 and are significantly higher than that in the Hot treatment, with average earnings of 24 (Wilcoxon-Mann-Whitney test, $\mathrm{p}<0.01$ ).

Figure 2 presents agents' effort partitioned by wage offers. The significant difference in agents' effort between the Cold and Hot treatment is mainly found for medium wage offers (Wilcoxon-Mann-Whitney test, $\mathrm{p}<0.01$ ). For low wage offers there is no expectation of reciprocity in either condition and for high wage offers there are insufficient observations.

These results suggest that the hypothetical elicitation of decisions "forces" agents to think through both contracts more carefully. This process appears to "cool down" their resentful emotions resulting in higher effort as compared to when they lack this opportunity and their responses are elicited "on the spot."

Additionally, it is helpful to understand whether this "cooling effect" is more pronounced in the early or late periods. In this experiment, subjects played for ten periods. If the "cooling effect" occurs, it is expected to be stronger as subjects gain more experience. The evidence is provided as follows.

RESULT 2. When principals choose the control contract, the difference in agents' effort between the Hot treatment and the Cold treatment mainly occurs in the later periods.

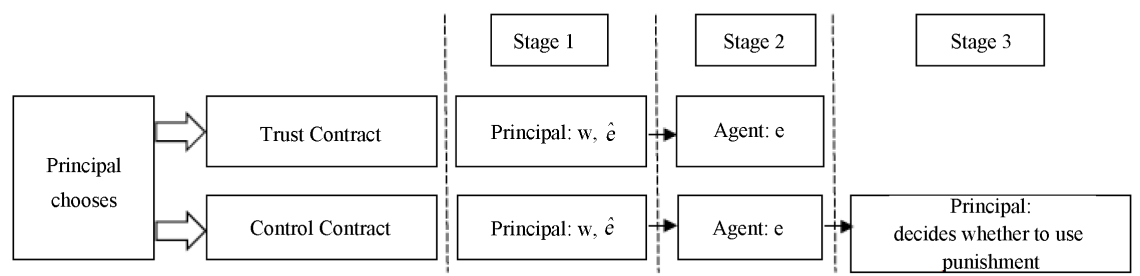

Figure 1. Timeline of decisions.

Table 1. Summary statistics mean (Standard deviation).

\begin{tabular}{ccccc}
\hline & \multicolumn{2}{c}{ Hot Treatment } & \multicolumn{2}{c}{ Cold Treatment } \\
\hline & Control Contract & Trust Contract & Control Contract & Trust Contract \\
\hline Wage & 47 & 56 & 44 & 48 \\
Agent's Effort & $(16)$ & $(24)$ & $(16)$ & $(21)$ \\
& 0.35 & 0.34 & 0.4 & 0.28 \\
Principal's Payoffs & $(0.26)$ & $(0.27)$ & $(0.26)$ & $(0.22)$ \\
& 24 & 20 & 28 & 19 \\
Agent's Payoffs & $(18)$ & $(15)$ & $(18)$ & $(14)$ \\
& 41 & 52 & 37 & 45 \\
Number of Observations & $(15)$ & $(22)$ & $(15)$ & $(19)$ \\
& 583 & 67 & 154 & 46 \\
\hline
\end{tabular}




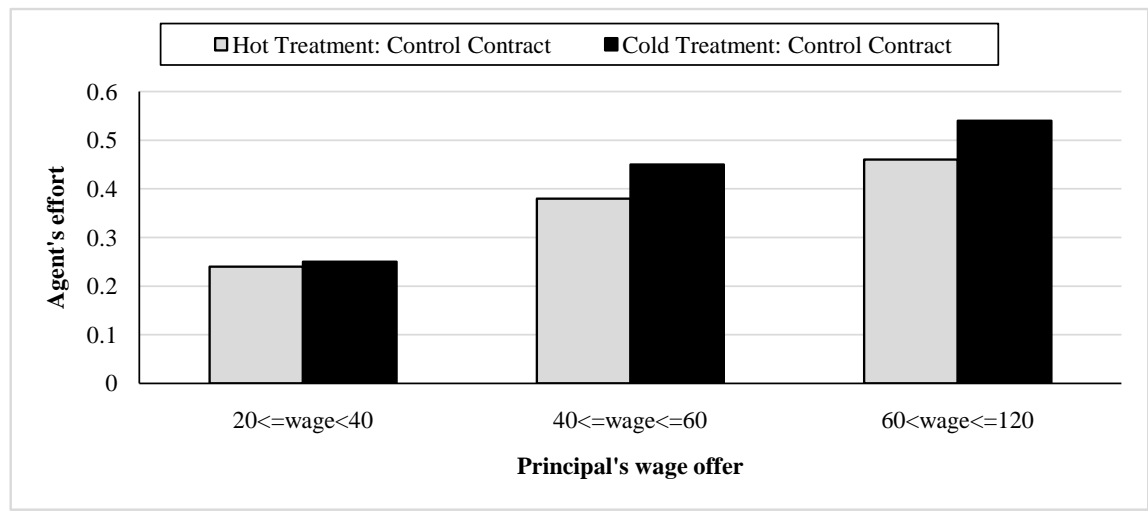

Figure 2. Agent's effort across treatments.

Figure 3 presents agents' effort over time. The figure reveals that in the first three periods when principals choose the control contract, agents' effort is almost identical between the Cold and the Hot treatment. Moreover, from the fourth period, agents' effort in the Cold treatment starts to exceed the effort in the Hot treatment (Wilcoxon-Mann-Whitney test, $\mathrm{p}=0.02$ in period 8 and $\mathrm{p}=$ 0.09 in period 10). One plausible interpretation is that, as agents gain experience with making contingent effort choices in the Cold treatment, repeated opportunities to "cool off" may help agents react even less emotionally in the later periods. By contrast, agents put "on the spot" may have difficulty making unemotional decisions even when doing so repeatedly.

\section{Discussion}

This study finds that the strategy method can be a "cooling down" mechanism to mitigate agents' emotional resentment of controls. Despite the fact that there is no clear consensus in theories about the determinants on when these two methods are different, this study provides additional evidence to support a prediction in the prior literature that subjects react less emotionally, and potentially more strategically, when asked to respond to multiple alternative choices in the strategy method than the direct response method.

[1] found no significant difference in agents' effort in a gift-exchange game between these two methods. In their study, principals can impose a control which restricts agents' strategy space. It is possible that their control is so intrusive that it can be clearly interpreted as a strong signal of distrust by agents even when the strategy method is applied. However, the control this study employed is inherently much less intrusive than the control in [1] because it does not restrict agents' strategy space and principals retain the option not to use it. A control of this type is more likely to appear legitimate to agents when they have the opportunity to consider it carefully, resulting in less emotional resentment. Therefore, this study's "Cold" elicitation method is likely to be more effective in reducing agents' negative responses to controls than the one in [1].

This suggests that the behavioral differences between these two elicitation 


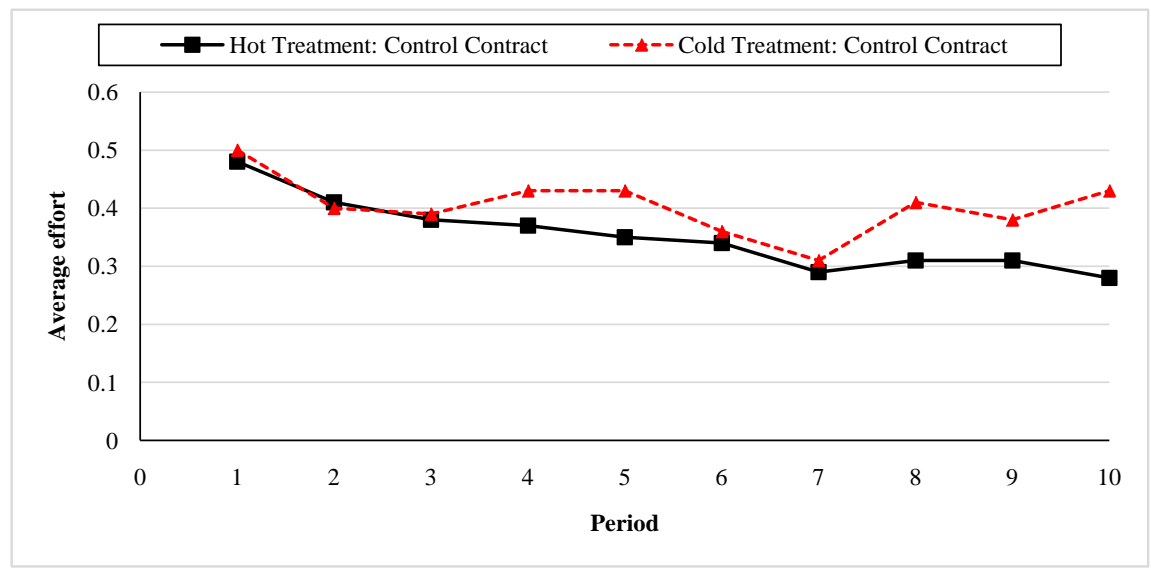

Figure 3. Agent's effort by periods.

methods may depend on how strongly agents' emotions are aroused by the experimental manipulation. If the emotion is too strong, it is likely that the strategy method is inadequate to mitigate the emotional reaction. Likewise, if the emotion is weak, it is likely that the strategy method can be helpful to suppress it. Future research could manipulate the strength of emotions and explore whether it affects behavioral differences between these two methods.

\section{Acknowledgements}

Thanks to Anil Arya, John Kagel, Douglas Schroeder, Steve Schwartz and Richard Young for their comments and suggestions. This research was sponsored by The Ohio State University Department of Accounting and MIS.

\section{References}

[1] Falk, A. and Kosfeld, M. (2006) The Hidden Costs of Control. American Economic Review, 96, 1611-1630. https://doi.org/10.1257/aer.96.5.1611

[2] Fehr, E. and List, J. (2004) The Hidden Costs and Returns of Incentives-Trust and Trustworthiness among CEOs. Journal of the European Economic Association, 2, 743-771. https://doi.org/10.1162/1542476042782297

[3] Fehr, E. and Rockenbach, B. (2003) Detrimental Effects of Sanctioning on Human Altruism. Nature, 422, 137-140. https://doi.org/10.1038/nature01474

[4] Kuang, X. and Moser, D. (2009) Reciprocity and the Effectiveness of Optimal Agency Contracts. The Accounting Review, 84, 1671-1694. https://doi.org/10.2308/accr.2009.84.5.1671

[5] Xiao, E. and Houser, D. (2005) Emotion Expression in Human Punishment Behavior. PNAS, 102, 7398-7401. https://doi.org/10.1073/pnas.0502399102

[6] Brandts, J. and Charness, G. (2011) The Strategy versus the Direct-Response Method: A First Survey of Experimental Comparison. Experimental Economics, 14, 375-398. https://doi.org/10.1007/s10683-011-9272-x

[7] Armantier, O. (2006) Do Wealth Differences Affect Fairness Considerations? International Economic Review, 47, 391-429.

[8] Fong, Y.F., Huang, C.Y. and Offerman, T. (2007) Guilt Driven Reciprocity in a Psychological Signaling Game. Working Paper, University of Amsterdam. 
[9] Fischbacher, U. and Gachter, S. (2010) Social Preferences, Beliefs, and the Dynamics of Free Riding in Public Goods Experiments. American Economic Review, 100, 541-556. https://doi.org/10.1257/aer.100.1.541

[10] Fehr, E., Kirschsteiger, G. and Reidl, A. (1993) Does Fairness Prevent Market Clearing: An Experimental Investigation. The Quarterly Journal of Economics, 108, 437-459. https://doi.org/10.2307/2118338

[11] Fischbacher, U. (2007). z-Tree: Zurich Toolbox for Ready-Made Economic Experiments. Experimental Economics, 10, 171-178.

https://doi.org/10.1007/s10683-006-9159-4 